\title{
Design and Implementation of Artificial Intelligence Powered Agriculture Multipurpose Robot using Raspberry Pi
}

\author{
Vaishnavi D. Patil \\ Department of Electrical Engineering \\ Padmbhushan Vasantraodada Patil Institute of Technology \\ Budhgaon. Sangli, INDIA \\ vaishnavidpatil1998@gmail.com
}

\author{
Kashim R. Basaragi \\ $K$ B Project solutions \\ INDIA \\ kasimbasaragi@gmail.com
}

\begin{abstract}
The agriculture field faces many problems such as crop diseases problem, pest outbreak problems, water problems, weeds, large use of fertilizer, and many more. These problems lead to crop loss, economic loss and also cause severe environmental problems due to the current agriculture practices. The AI and Robot Technologies had the potential to solve these problems very smartly. As agriculture is a dynamic sector, the problems in agriculture are not mid-core by AI and robotics, and a specific solution is provided to an expressly daedal problem. Diversity of systems have been developed to minimize and provide a better approach to the world. This paper contains significant contributions used to address the challenges that agriculture faces and through $\mathrm{AI}$ and robotic technology we eliminate problems.
\end{abstract}

Keywords- Artificial intelligence (AI), Artificial Neural Network (ANN), Robotics Technology.

\section{INTRODUCTION}

Agriculture is one of the most dominating fields of the economic sector. According to Worldbank.org, agriculture accounted for $4 \%$ of the world's GDP in 2018 and can account for about $18 \%$ of the nation's GDP for countries like India [1]. Being a farmer, the farmer had to face many problems right from sowing to harvesting. Particular factors such as unexpected climate behaviors', continuously changing global warming, water shortage problems, insect and disease infestation, limitless use of pesticides, weeds, underirrigation, and drainage, along with these Laboure shortage is another dominating problem.

Established farming methods are incapable of producing food to feed the future population of the world. It also risks people's health and the planet. These threats have driven the agriculture sector into finding more innovative ideas and technology for improving crop outturn. from the last century, agriculture has moved from Laboure-rigorous to automation and power- rigorous production systems. Although, agriculture has begun to digitize over the last 15 years. AI and robotics are a sturdy unification for automating any tasks. In recent years, AI has become a progressively universal presence in the robotic sector, instigate learning and adaptability in until now rigid applications [3]. Agriculture is a sundry sector, which means a common approach can-not advise for every state. The AI and robotics techniques help one to collect the data of each condition and feed a required solution to a given problem. AI and roboticsbased technologies have the inherent to solve these threats efficiently. These technologies can improve crop outturn and production, irrigation by using limited water, crop monitoring, quality of the crop. AI and robotics-based technologies can authorize the farmer to produce more and better outturn with minimize manufacturing cost and increase their profit.

\section{BLOCK DIAGRAM}

For designing this AI-powered agriculture robot we are using a Raspberry Pi P3 CPU kit for computing. In this paper, we are using a machine learning technique for teaching our machine. On the input side we using three types of sensors which a Pi Camera, Humidity sensor, IR sensor. On the output side pesticide motor driver and pesticide pump for pumping pesticide. For control, a Humidity water motor driver and water pump will be installed. For dumping solid fertilizer, we using a motorized ON/OFF valve. For moving robots autonomously on the path, we use an IR sensor for detection of the path, and as output action motor will run as per IR sensed the path fig. 1 shows a block diagram and fig. 2 shows circuit diagram.

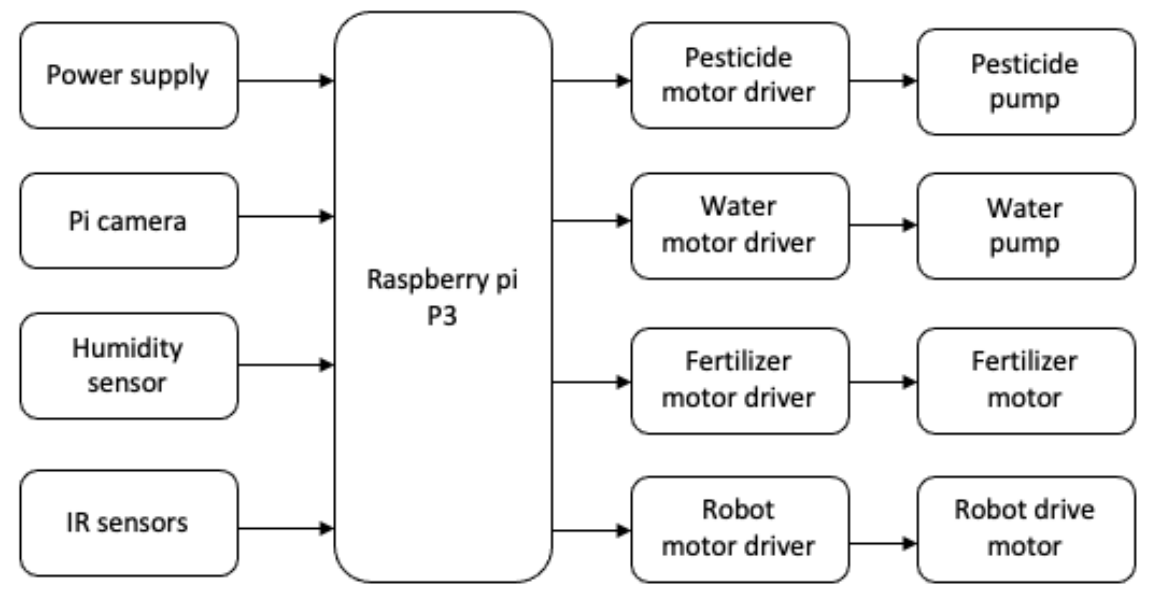

Fig. 1. Block Diagram of Control unit 


\section{CIRCUIT DIAGRAM}

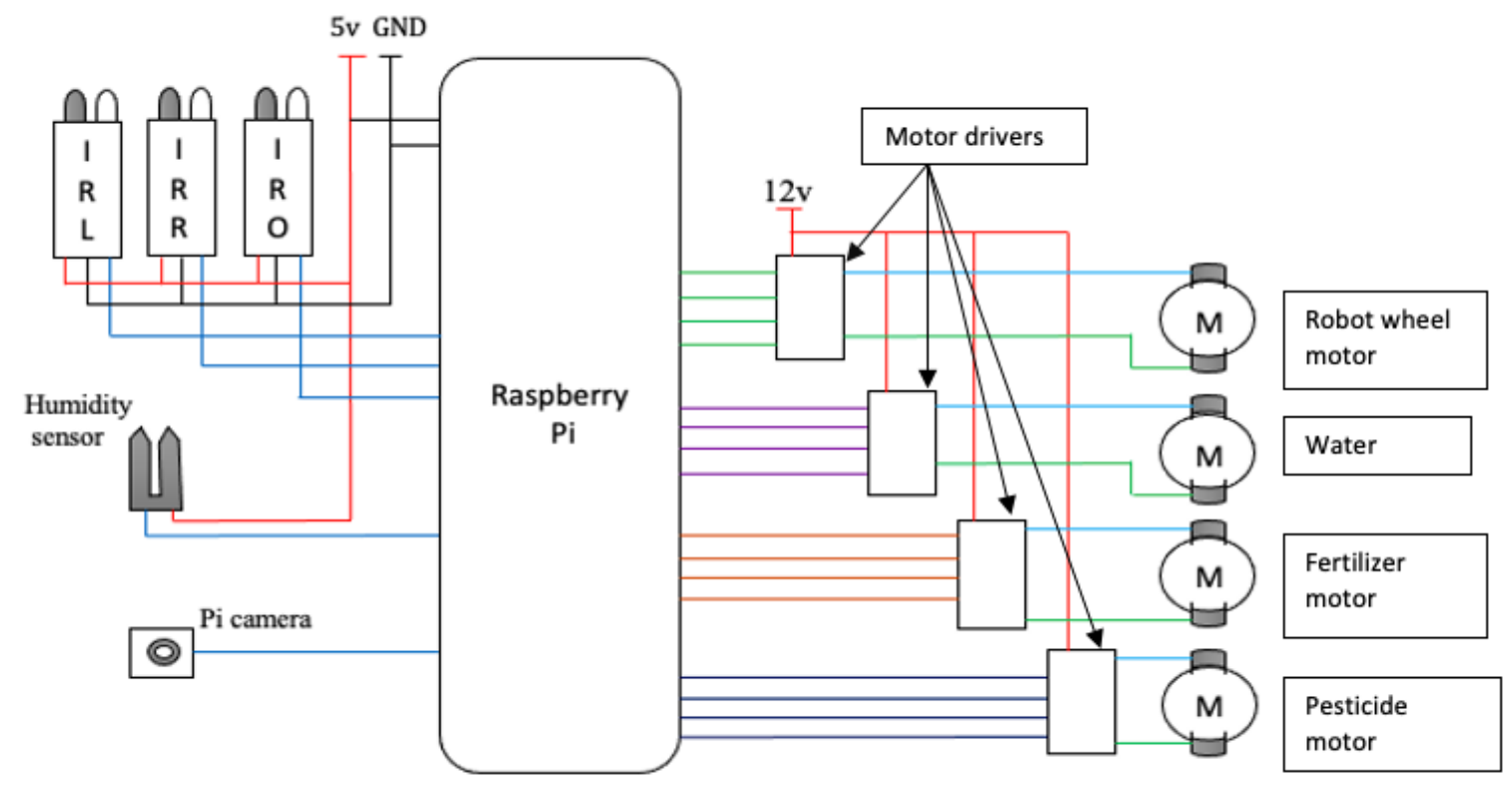

Fig. 2. Circuit Diagram of Control unit

\section{OPERATION}

For controlling the robot, we are using a Raspberry Pi P3 CPU. It had to boast a 64-bit quad-core processor running at $1.4 \mathrm{GHz}$, dual-band $2.4 \mathrm{GHz}$ and $5 \mathrm{GHz}$ wireless LAN, Bluetooth 4.2/BLE, faster Ethernet, and PoE capability via a separate PoE HAT, 1GB LPDDR2 SDRAM, $2.4 \mathrm{GHz}$ and $5 \mathrm{GHz}$ wireless LAN, Bluetooth 4.2 , BLE, Gigabit Ethernet over USB 2.0 (maximum throughput $300 \mathrm{Mbps}$ ) $4 \times$ USB 2.0 ports, and 40 IO pins which gives us fast operating speed. In our system, we are teaching machines to act like humans this process called artificial inelegancy. In AI we using Artificial Neural Network (ANN) for machine learning [4].

\section{A. Artificial Neural Network(ANN) and Machine Learning -}

ANN is a processing algorithm or hardware whose functioning is inspired by the design and functioning of a human brain. Neural networks have a remarkable ability of self-learning and they had replaced many traditional methods. An artificial neural network (ANN) is a

\section{B. Artificial Neural Model}

computing system designed to simulate the way the human brain analyses and processes information. It is the basics of artificial intelligence (AI) and solves problems that would prove impossible or difficult by human or statistical standards. ANNs have self-learning capabilities that enable them to produce better results as more data becomes available. Artificial neural networks are built like the human brain, with neuron nodes interconnected like a web fig. 3.

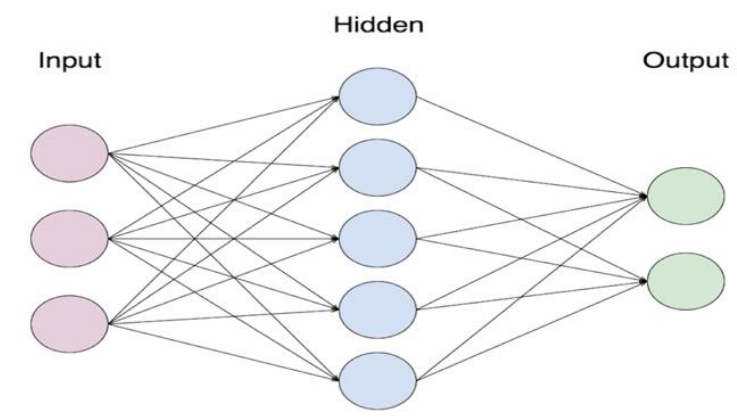

Fig. 3. Artificial Neural Network

\section{$\mathrm{X} 1$}

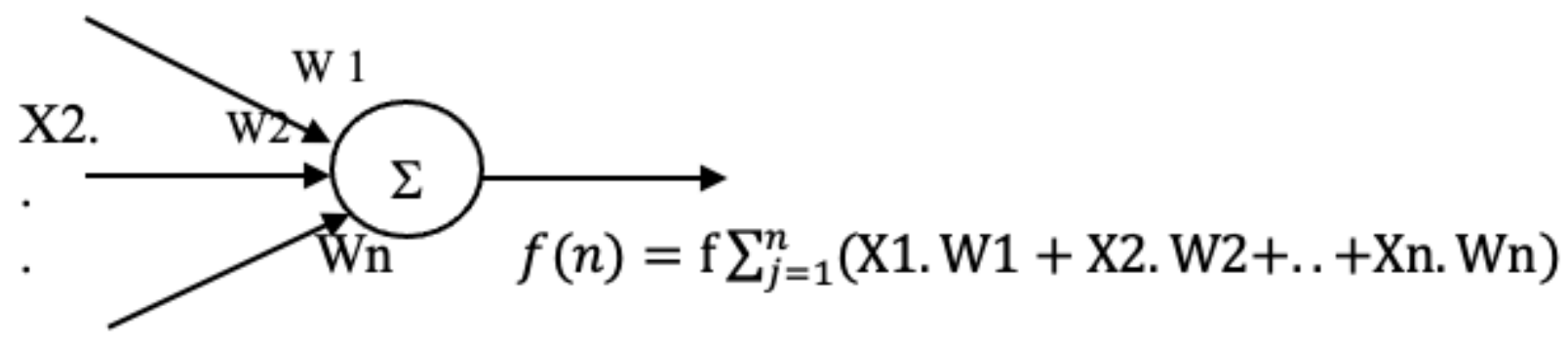

$\mathrm{Xn}$ 
TABLE I. IR BASED ROBOT RUNNING OPERATION

\begin{tabular}{|c|c|c|c|c|}
\hline Sr. No & IR sensor surface sense & signal & Left motor & Right motor \\
\hline 1. & Both sensor on white & Both=1 & Forward & Forward \\
\hline 2. & $\begin{array}{c}\text { Left on the black right on } \\
\text { the white }\end{array}$ & Left= 0, right=1 & Reverse & Reverse \\
\hline 3. & $\begin{array}{c}\text { Left on the white right on } \\
\text { black }\end{array}$ & Left=1, right=0 & Sorward & Stop \\
\hline 4. & Both on black & Both=0 & Stop & \\
\hline
\end{tabular}

\section{IR based robot running operation}

In our AI robot for navigation, we using an IR sensor to find a path and stay on the path in robot run time. IR sensor senses the light on the surface and gives a high low signal to the microcontroller. The microcontroller reads the data which is given by the IR sensor and controls the motoring operation [5]. We controlling a robot using raspberry Pi and we want to act this robot autonomously. After the robot reached its stop condition robot will stop for 24 hours and again it will turn on itself and start working again in the below table. 1 shows how IR senses the surface and how the motor will act.

\section{Object detection and stopping action and Humidity sensing}

For the detection of the plant, we using a black patch to detect the plant using an IR sensor. When the robot travel in front of plants one IR sensor is connected at the side of the robot. While it passes the black patch then the robot will stop for few times. In that time humidity sensor is getting in action and it takes humidity of the soil and send data to the microcontroller. The microcontroller is deciding humidity [6]. If humidity is incorrect then the water pump will start by the microcontroller and spray the water at the root side of plants.

\section{E. Image processing}

A Pi camera is connected on the top of the robot to monitor the area for spraying pesticide it takes pictures of the area and sends them to the microcontroller continually. The microcontroller is doing a comparison between plant, soil, and grass if there is the grass is detected our microcontroller will give the order to spray the pesticide otherwise it will keep monitoring [7].

\section{RESULTS-}

A. Motoring results-

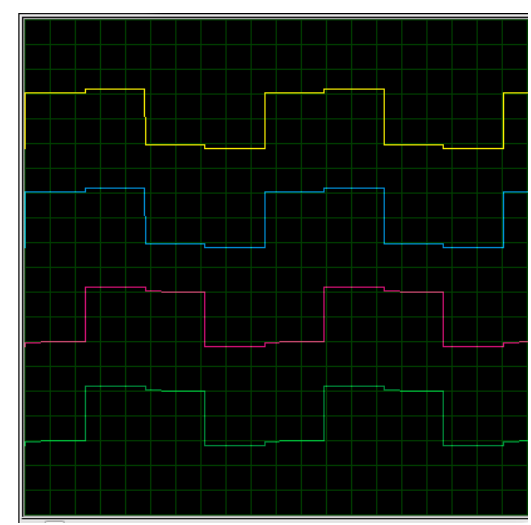

Fig.4 motors in Forward direction Waveforms

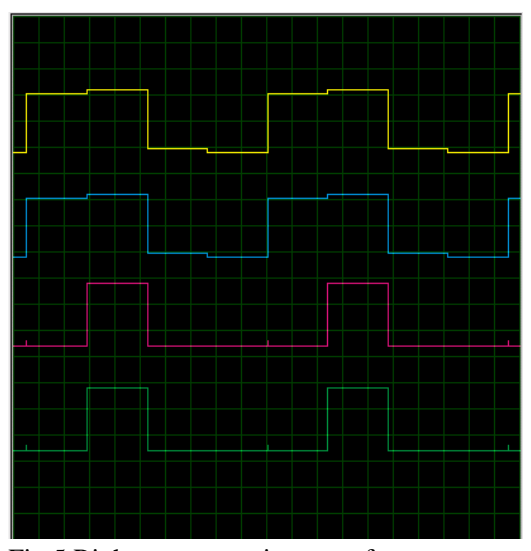

Fig.5 Right turn operation waveforms

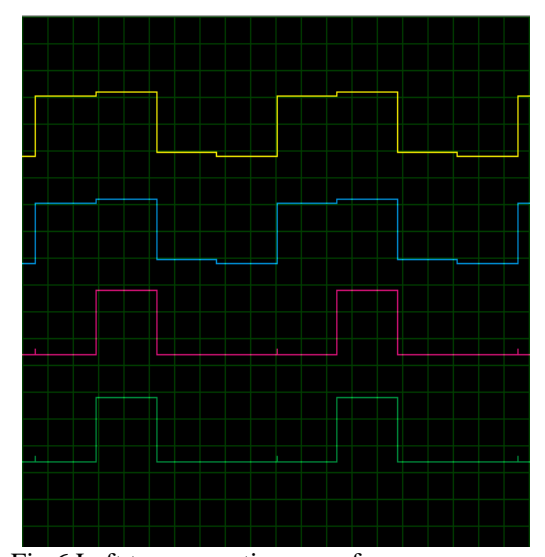

Fig.6 Left turn operation waveforms

B. Object detection and stopping action and Humidity sensing hardware result-

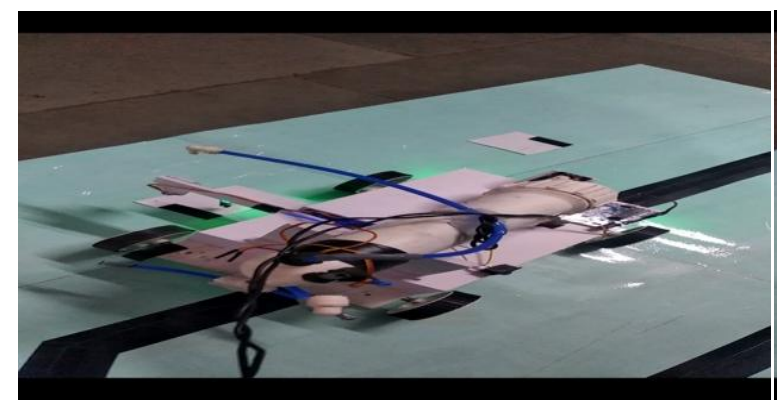

Fig.7 first object detected

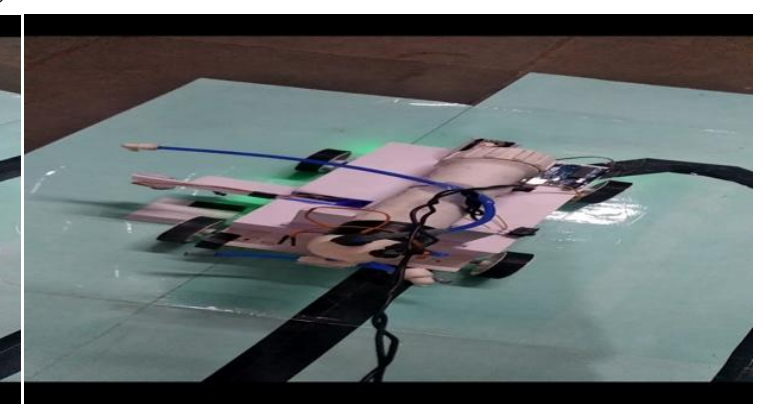

Fig.8 Second object detected 


\section{CONCLUSION}

Not only do these autonomous robots improve efficiency, but they also reduce the need for unnecessary pesticides and herbicides. Besides this, farmers can spray pesticides and herbicides effectively in their farms with the robot, and plant monitoring is also no longer a burden.

\section{REFERANCE}

[1] The world bank.org, "Agriculture Overview," Sep. 30, 2020. https://www.worldbank.org/en/topic/agriculture/overview (accessed Dec. 14, 2020).

[2] H. Ai, "Artificial intelligence in the design of the transitions to sustainable food systems change Camarena," vol. 271, 2020, DOI: $10.1016 /$ j.jclepro.2020.122574.
[3] Robotics online, "How AI is Used in Today's Robots |RIA Blog| RIA Robotics Blog," Nov. 09, 2018. https://www.robotics.org/blog- article com/How-Artificial-Intelligence-is-Used-in-Today-s- Robots/117 (accessed Dec. 14, 2020).

[4] Raspberry Pi Documentation by the Raspberry Pi Foundation.

[5] L. Paul Jasmine Rani; M. Khoushik Kumar; K. S. Naresh; S. Vignesh, "Dynamic traffic management system using infrared (IR) and Internet of Things (IoT)", IEEE2017.

[6] B. Harish Kumar, "WSN based Automatic Irrigation and Security System using Raspberry Pi Board” IEEE, 2017.

[7] Mochammad Ariyanto; Ismoyo Haryanto; Joga Dharma Setiawan; M. Munadi; M. Sri Radio, "Real-Time Image Processing Method Using Raspberry Pi for a Car Model”, IEEE 2019.

[8] Hagan, Demuth, and Beale "Artificial Neural Networks slides". 